\title{
Restrictions delay fossil hunts in Ethiopia
}

Rex Dalton, Kansas City

Disputes over access to some of the world's richest fossil sites are disrupting research on human evolution, according to those working in the field.

Some Ethiopian researchers say new rules have forced them to leave productive sites and stopped them studying their discoveries by denying them laboratory access. And at least one Ethiopian doctoral candidate's degree could be jeopardized by the situation.

Disagreements over site access have been simmering since early 2000 . But the dispute heated up considerably last summer when the Ethiopian government introduced new regulations to control physical anthropology projects. The regulations and their impact were the subject of much discussion last month at the annual meetings of the American Association of Physical Anthropologists and the Paleoanthropology Society in Kansas City, Missouri.

The regulations were announced last year by the Ethiopian Authority for Research and Conservation of Cultural Heritage. They set time limits for research, require payments for the use of laboratory facilities - and ask foreign research teams to give up their equipment and vehicles at the end of the project.

But the rules are viewed by some palaeoanthropologists as biased and damaging to research efforts. And some researchers fear that the rules might not be applied equally to all teams.

Sileshi Semaw, an Ethiopian anthropologist and archaeologist who is now a postdoctoral fellow at Indiana University, believes that the regulations will make it increasingly difficult to do research at the National Museum of Ethiopia and in the field. But he remains optimistic: "Eventually the Ethiopian government will realize what is going on and make a change," he says.

The US National Science Foundation (NSF) is also worried about the regulations, which, officials there say, conflict with NSF policies on the disposal of equipment purchased with the agency's grant money. Last month, Mark Weiss, director of the NSF's physical anthropology programme, met with the Ethiopian ambassador in Washington to discuss the issue. The talks were cordial, says Weiss, with the ambassador saying that concerns would be examined.

Last week, Brook Hailu, deputy Ethiopian ambassador to the United States, said that it is "the general policy of the Ethiopian government that people of high calibre can conduct research". The government will examine the new regulations to see if changes need to be made, said Hailu. "I have no doubt that our government will cancel partially or in total any regulations found to be

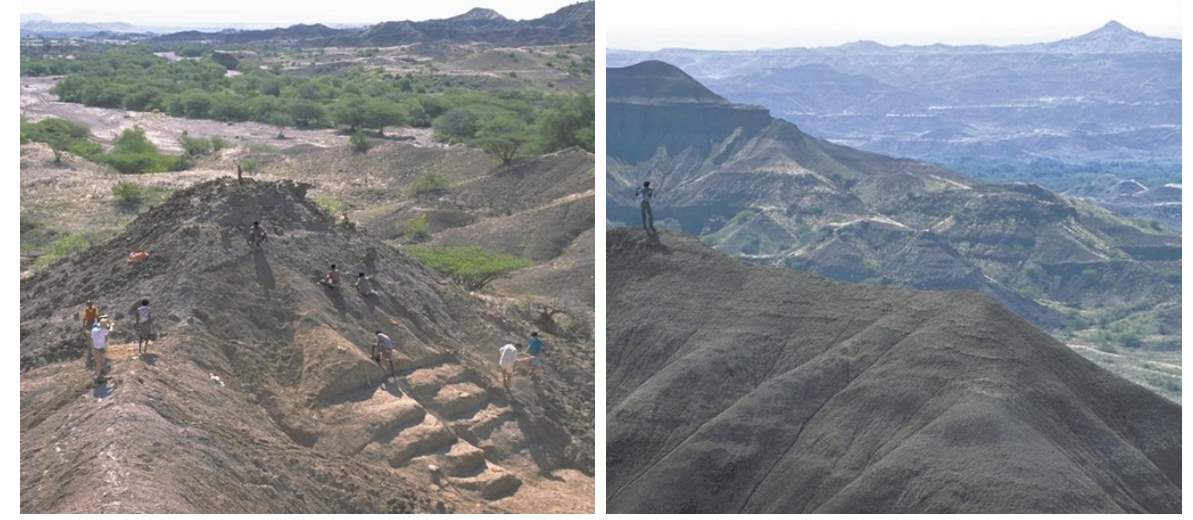

Rich pickings: Ethiopian sites are yielding large numbers of hominid fossils.

negative," he added.

There have been plenty of disputes before over research access in Ethiopia, but the present row has arisen over a rewarding site called Galili, about 300 kilometres northeast of Addis Ababa.

Yohannes Haile Selassie, an Ethiopian doctoral candidate at the University of California, Berkeley, spent three years studying this site, finally finding important hominid fossils there in 1998. But in February 2000, an Austrian team headed by Horst Seidler arrived at the site, saying it had government permission to conduct field research there.

Haile Selassie says that the regulations "kicked me out of my site". Since then, he says, he has been unable to conduct analysis on specimens at the National Museum laboratory in Addis Ababa or continue field studies at Galili. His doctoral degree is threatened because he has now exceeded the three-year limit enforced by the Ethiopian regulations.

When Haile Selassie's mentor, palaeoanthropologist Tim White, also at Berkeley, stood up for him, the Ethiopian fieldresearch permits for White's Middle Awash research team were suspended in February. White declined to comment.

But Middle Awash team geologist Giday WoldeGabriel, an Ethiopian now at Los Alamos National Laboratory in New Mexico, says that he thinks the regulations favour the Austrian team. "It makes me very angry," he says.

Insisting that he had nothing to do with formulating the Ethiopian regulations, Seidler, of Vienna's Institute of Anthropology, says he has conducted himself appropriately. "Haile Selassie was never displaced from his area," says Seidler, adding that the Ethiopian had not correctly defined his field site. "I have obtained my permit... in a transparent and legal way."

\section{PubMed Central offers deal on content}

\section{Meredith Wadman, Washington}

The website set up by the US National Institutes of Health (NIH) to provide free access to biomedical literature is making moves to quell publishers' unease over the status of online articles.

Organizers of PubMed Central (PMC) now say that participating journals can show free back content on their own websites, rather than displaying full text at the NIH site, as they were previously obliged to do.

PMC's backers say they hope that the policy - announced in an online forum on Nature's website last week and published on page 740 of this issue - will encourage many more journals to participate. So far, the NIH site, which was launched in February 2000, has signed up only eight journals. Organizers say that a dozen more are expected to sign up shortly.
"This [new policy] is much less scary for a lot of publishers," says David Lipman, director of the National Center for Biotechnology Information at the NIH. "Some publishers are just concerned about having their content viewed anywhere but their own site." Lipman says the policy change, which was made by the PMC's advisory committee late last month, is “a reasonable compromise".

Journals may now choose to link electronically to PMC, while keeping their content on their own website. In return, they must agree to make original research articles available on their website free of charge within a year of publication, and "preferably" within six months. The change represents a retraction of PMC officials' early insistence that publishers display entire articles at PMC. It comes as several 


\section{Funding battle heats up over large array}

Jonathan Knight, San Francisco

Astronomers around the world are gearing up to fight to secure funds for a large array telescope in the Andes that would help them study how galaxies are formed.

Such an instrument has been a top astronomy priority for years, and on 6 April research-agency representatives from Japan, North America and Europe met in Tokyo but promised only to try to reach agreement on its construction.

Funding for the Atacama Large Millimeter Array (ALMA) is not yet assured - particularly in the United States, which is supposed to pay about one third of its $\$ 660$ million construction costs.

The Bush administration's first budget proposal, issued in February, allowed no money for ALMA from the National Science Foundation (NSF), which funds groundbased astronomy in the United States.

The NSF had planned to start construction in 2002, using money it had meant to spend on the smaller Millimeter Array, a US project which was subsumed into ALMA. ALMA also absorbed Europe's Large Southern Array proposal and a Japanese project, the Large Millimeter and Submillimeter Array.

ALMA would be located on the Andean plateau in Chile, where the dry atmosphere will allow short-wavelength signals to reach the telescope. The most distant galaxies can be observed as they were when they first formed because it takes so long for their light to reach Earth. Dust around young stars blocks out most of the visible light in these galaxies, but the millimetre and submillimetre radiation shines through.

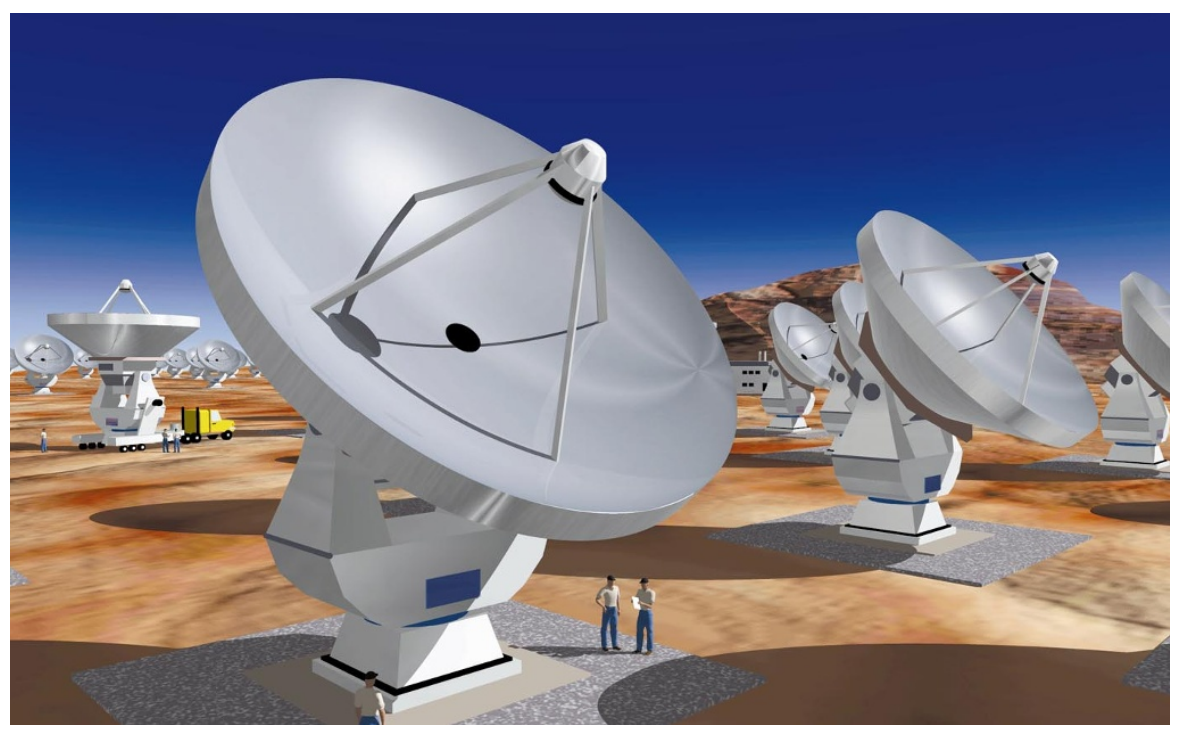

Star performer: the Atacama Large Millimeter Array would study the formation of distant galaxies.

"It means that you can make very detailed images of galaxies and stars in formation," says Bob Brown, deputy director of the National Radio Astronomy Observatory, which oversees the US contribution to ALMA.

ALMA's 64 12-metre dishes would simulate a dish of up to 14 kilometres across. Integrating the 64 signals would provide a resolution ten times better than that of the Hubble Space Telescope. As well as resolving very distant galaxies, ALMA should be able to detect planets in our own galaxy.

Funding for ALMA in 2002 is likely to be approved in Europe and Japan, but astronomers face an uphill battle in the United States. A panel of scientists has advised the
NSF that construction should proceed next year.

US researchers are preparing to take their case to Congress, which will consider the Bush proposal and develop a final 2002 budget by October. The Senate has indicated that it would like to give more money to the NSF than Bush proposed (see page 731).

Canada is expected to decide on a US\$30 million contribution later this month, says Ralph Pudritz, an astronomer at McMaster University in Hamilton, Ontario. Pudritz adds that no single country's contribution will be absolutely critical in 2002. "As long as the taps have started to turn on at some significant level, construction can begin," he claims.

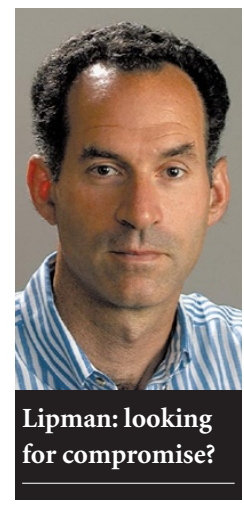

journals, including Science (see Nature 410, 502; 2001), are deciding to post free back content on their own websites, in most cases within a year.

The announcement is the latest development in the debate over how, when and at what price biomedical scientists will be able to access extensive electronic archives of published articles. Those involved in the discussion, including commercial and academic publishers, rebel scientists and librarians, are to meet next week (16-18 April) at Cold Spring Harbor Laboratory in New York state to discuss electronic publishing issues.
The meeting takes place against the backdrop of a threatened boycott by several thousand scientists, who have pledged to stop buying, publishing in or reviewing for journals that refuse to make their research articles freely available within six months.

Some publishers see the change as an acknowledgement by PMC of a failure to recruit the journals it needs to provide a near-exhaustive archive of biomedical literature. "They've lost that battle, now they're waving a white flag," says one commercial publishing executive, who declined to be identified. "They're saying they'll allow us to not deposit. Well, nobody was going to deposit anyway."

This executive says the PMC's new policy still does not guarantee journals an adequate return. "They are [still] basically trying to pin publishers down to say 'any income we make we will make in the first six months, at most a year'. That's not a model that most publishers know whether they can accept."

Catherine DeAngelis, editor of the Journal of the American Medical Association, calls the new policy "a step in the right direction" because it will allow journals to retain material on their own websites. But she bristles at the demand that journals that link to the site make back content free within a year. "I would love the whole world to get [our content] immediately. But our journal would go under if we didn't have money to run it," she said.

Other publishers say that the change could help the PMC to recruit more journals. Martha Howe, president of the American Society for Microbiology, which publishes ten journals, says that "it may well make participation easier". 